\title{
Substudy Planned Indicator
}

National Cancer Institute

\section{Source}

National Cancer Institute. Substudy Planned Indicator. NCI Thesaurus. Code C126076.

An indication as to whether a study performed on a subgroup of subjects included in the

original trial is planned to be included as part of the current study. 